\title{
O CENÁRIO ATUAL DA EDUCAÇÃO NO BRASIL E A IMPLANTAÇÃO DO MODELO EDUCACIONAL CÍVICO-MILITAR
}

\author{
THE CURRENT SCENARIO OF EDUCATION IN \\ BRAZIL AND THE IMPLEMENTATION OF THE CI- \\ VIC-MILITARY EDUCATIONAL MODEL
}

\author{
Claudio Sales Barbosa ${ }^{1}$ \\ Allison José dos Santos ${ }^{2}$ \\ Paulo Henrique de Assis Brazil ${ }^{3}$ \\ Danielle Farias Vitorino Brazil ${ }^{4}$ \\ Flávia Paes de Lima Siqueira ${ }^{5}$ \\ Djessyca Steffane Silva de Lima ${ }^{6}$
}

Resumo: O presente estudo des- al educacional do Brasil em se taca uma análise do cenário atu- vê no desafio de fomentar novos

1 Especialista MBA em Gestão Pública pela UFF - RJ. Graduado em Secretariado Executivo pela UNIFACEX. Subcoordenador Regional - Nordeste - no PECIM. Militar, Brasil

2 Especialista em Psicopedagogia pela FAJOLCA. Pedagogo. Professor da Rede de Ensino do Jaboatão dos Guararapes, PE, Brasil

3 Mestre em Economia pela UFPB. Contador do IFRN, Campus Parnamirim, RN, Brasil

4 Especialista em Contabilidade pública pela UGF. Técnica em Contabilidade do IFRN - Campus São Paulo do Potengi, RN, Brasil

5 Especialista em Gestão de Pessoas nas Organizações - FADEPE. Administradora do IFPE- Campus Garanhuns, PE, Brasil (desde 2011

6 Especialista em Psicologia Infantil pela FAVENI. Psicóloga. Coordenação de Apoio ao Ensino e ao Estudante (CAEE) / Instituto Federal de Educação Ciência e Tecnologia de Pernambuco, Campus Garanhuns, PE, Brasil

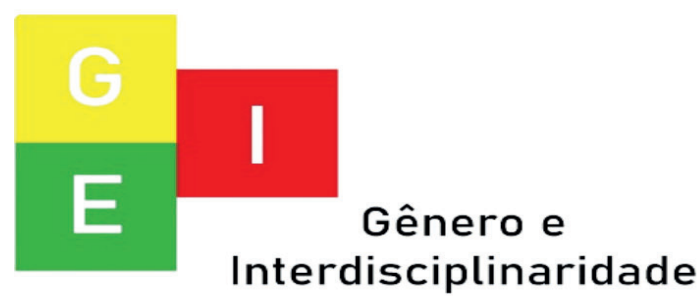


ISSN: 2675-7451

Vol. 02 - n 03 - ano 2021

Editora Acadêmica Periodicojs

modelos educacionais de qualidade, capazes de elevar o nível de aprendizado que proporcionarão melhores oportunidades aos jovens, com a consequente redução da desigualdade social no país. O Governo Federal, então, ciente do seu papel frente a essa situação, por meio do Decreto $\mathrm{N}^{\circ} 10.004$, de 5 de setembro de 2019, lançou o Programa Nacional das Escolas Cívico-Militares, o PECIM, que traz um modelo de gestão nas áreas educacional, didático-pedagógica e administrativa, alinhada à Base Nacional Comum Curricular (BNCC). O objetivo deste trabalho é analisar a literatura sobre o cenário atual da educação no Brasil sob o enfoque da implantação do modelo educacional cívico-militar. Como metodologia optou-se por uma pesquisa básica e bibliográfica. Para coleta de dados, utilizou-se de revisão de literatura de análise de fontes bibliográficas primárias. Partindo do ponto de vista complexo das questões discutidas, tratadas e, sobretudo, dos dados analisados no universo deste estudo, foi possível formular considerações, apresentando um conjunto de conclusões na tentativa de mostrar a dimensão do olhar sobre o cenário atual acerca da qualidade da educação básica em escolas públicas e a concepção do modelo educacional cívico-militar. Na perspectiva do direito à educação com qualidade o modelo cívico-militar pode contribuir para a melhoria do comportamento de alunos no ambiente familiar, escolar e social. Bem como, entende-se que há relevância da parceria dos órgãos militares com a escola pública para melhoraria da qualidade da educação básica com ênfase no acesso, na permanência e na aprendizagem, significa-

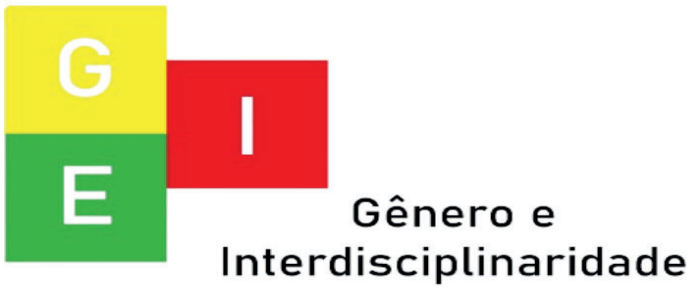


tivamente.

Palavras-chave: Cívico-militar. Educação. Sistema de ensino.

Abstract: This study highlights an analysis of the current educational scenario in Brazil in the challenge of fostering new quality educational models, capable of raising the level of learning that will provide better opportunities for young people, with the consequent reduction of social inequality in the country. The Federal Government, then, aware of its role in this situation, through Decree No. 10.004, of September 5, 2019, launched the National Program of Civic-Military Schools, PECIM, which brings a management model in educational, didactic-pedagogical and administrative areas, in line with the Common National Curriculum Base (BNCC). The aim of this paper is to analyze the literature

on the current educational scenario in Brazil from the standpoint of the implementation of the civic-military educational model. As a methodology, a basic and bibliographical research was chosen. For data collection, we used a literature review and analysis of primary bibliographic sources. Starting from the complex point of view of the issues discussed, dealt with and, above all, the data analyzed in the universe of this study, it was possible to formulate considerations, presenting a set of conclusions in an attempt to show the dimension of the view on the current scenario regarding the quality of education in public schools and the conception of the civic-military educational model. From the perspective of the right to quality education, the civic-military model can contribute to improving the behavior

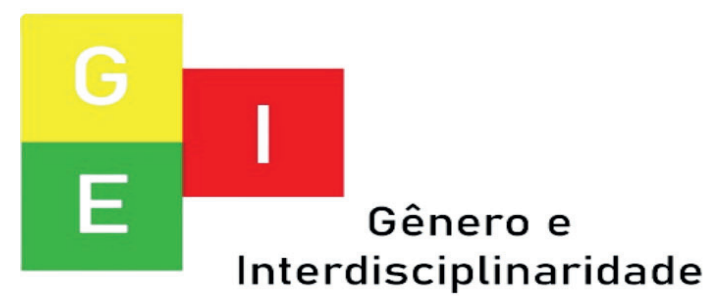


ISSN: 2675-7451

Vol. 02 - n 03 - ano 2021

Editora Acadêmica Periodicojs

of students in the family, school and social environment. As well, it is understood that the partnership between the military bodies and the public school is relevant to significantly improve the quality of basic education with an emphasis on access, permanence and learning.

Keywords: Civic-military. Education. Education system.

\section{INTRODUÇÃO}

Atualmente, a real situação da qualidade da educação brasileira tem sido desafiadora em diferentes extremidades do país, devido aos altos índices de baixa qualidade no ensino. Seu sistema educacional tem apresentado falhas na forma de lidar com a gestão escolar e didático-pedagógica, o que por sua vez tem comprometido o processo de ensino e aprendizagem. Diante desse cenário, o país se vê no desafio de fomentar novos modelos educacionais de qualidade, capazes de elevar o nível de aprendizado que proporcionarão melhores oportunidades aos jovens, com a consequente redução da desigualdade social no país. O Governo Federal, então, ciente do seu papel frente a essa situação, por meio do Decreto $\mathrm{N}^{\circ} 10.004$, de 5 de setembro de 2019, lançou o Programa Nacional das Escolas Cívico-Militares, o PECIM, que traz um modelo de gestão nas áreas educacional, didático-pedagógica e administrativa, alinhada à Base Nacional Comum Curricular (BNCC). Tomou-se por base, ainda, as experiências adquiridas nos modelos de alto nível educacional dos Colégios militares do Exército, da Polícia Militar e do Corpo de Bombeiros militares, os quais têm apresenta-

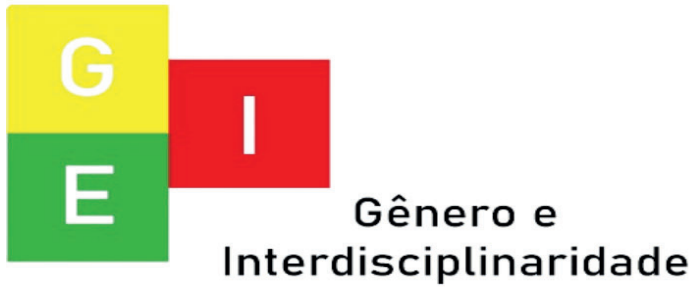


ISSN: 2675-745

Vol. 02 - n 03 - ano 202

Editora Acadêmica Periodico

do melhores indicadores, em relação às escolas civis, com taxas de abandono escolar 70\% menor e taxa de reprovação de $37 \%$ inferior, mesmo com a aplicação da funesta política de aprovação automática, adotada por Estados e Municípios para maquiar indicadores de desempenho educacional (BRASIL, 2019).

É com base neste contexto que o Ensino Cívico Militar pode ser uma boa modalidade de gestão educacional em escolas públicas. Já que é notório o prejuízo que os diversos fatores internos, tais como: distração, sequestro de tempo útil, discussões entre alunos, excesso de brincadeiras, sucessivas reprovações, falta de incentivo da escola causam no processo de ensino e aprendizagem (SILVA-FILHO e ARAÚJO, 2017).

É por isso que a educação é um dos pilares para a evo- lução de qualquer sociedade que pretende ser mais justa, transformadora, determinada e fraterna (SAVANI, 2014). Ela é um pré-requisito elementar para o desenvolvimento político, social e econômico, para a democracia e para a igualdade social. É com essa visão que o modelo de Ensino Cívico Militar tem sido proposto, dando ênfase à valorização dos profissionais, à ampliação das condições de acesso e permanência na escola, à melhoria da qualidade do ensino oferecido, garantindo a equidade. Pautado nesta abordagem, o presente artigo visa responder a problemática em estudo: Qual o real cenário atual da educação no Brasil e qual os benefícios da implantação do modelo educacional cívico-militar?

Portanto, mediante os aspectos supracitados, este estudo teve como objetivo analisar a




ISSN: 2675-7451

Vol. 02 - n 03 - ano 2021

Editora Acadêmica Periodicojs

literatura sobre o cenário atual da educação no Brasil sob o enfoque da implantação do modelo educacional cívico-militar. E em seus específicos, analisar a literatura acerca do real cenário da educação brasileira mediante os dados apresentados pelo PISA; conhecer as alterações nos projetos políticos pedagógicos das escolas públicas que passam adotar o modelo educacional cívico-militar; apontar as contribuições do modelo educacional cívico-militar para a melhoria da qualidade da educação básica, com ênfase no acesso, na permanência e na aprendizagem.

\section{MATERIAIS E MÉTODOS}

Este estudo trata de uma pesquisa básica e bibliográfica. Nesse sentido, foi realizada uma revisão bibliográfica de literaturas primárias disponível nas bases de dados eletrônicas

Scielo e Goole acadêmico. Foram

empregadas as seguintes categorias de descritores: Educação cívico-militar; Sistema de ensino cívico-militar; Implantação de escolas cívico-militares; Modelo de educação no Brasil; Educação básica; Educação no Brasil; Educação; Sistema de ensino; Programa Nacional das Escolas Cívico-Militares. Para coleta de dados a pesquisa eletrônica incluiu 12 trabalhos publicados entre 2009 e 2021 e 4 trabalhos publicados entre 1990 e 2000, em língua portuguesa, que abordasse as categorias de descritores, o que resultou em 16 publicações.

\section{RESULTAODS E DISCUS-} SÃO

\section{Barreiras enfrentadas no cená- rio atual da educação no Brasil}

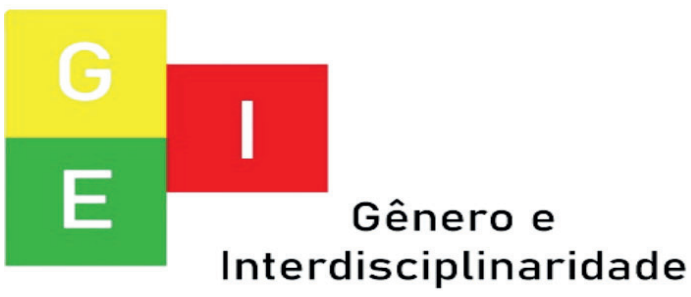


Atualmente, a educação brasileira vem enfrentando barreiras em seu cenário quando se refere aos seus amargos resultados no ranking da educação mundial, apesar de já ter adotado, ao longo da história, diferentes modelos teóricos. No entanto, é importante levar em consideração que o processo educacional está vinculado a diversos fatores, tais como: estrutura familiar, social, econômica e política. Esse conjunto de fatores pode contribuir e interferir no cenário apresentado quando se remete a educação no Brasil, visto que a educação é tida como um dos pilares para a evolução de qualquer sociedade que pretende a ser mais justa e fraterna. Ela é um pré-requisito elementar para o desenvolvimento político e econômico, para a democracia e para a igualdade social. Sendo assim, a valorização dos profissionais, a amplia- ção das condições de acesso e permanência na escola, a melhoria da qualidade do ensino oferecido e a equidade são alguns dos desafios que o país vem enfrentando.

No presente contexto, ser educador no Brasil, principalmente nas cidades afastadas da capital, é desafiador, pois as desvantagens são explícitas: ausência de uma tecnologia de suporte, ociosidade cognitiva dos alunos e suas famílias, precarização do papel e do valor do professor, falta de estrutura nas escolas, de biblioteca e centros de formação continuada são apenas algumas delas. Ainda é muito forte o sentimento da falta de valorização quanto à remuneração dos profissionais da Educação. As condições desses trabalhadores têm imposto uma situação muito precária que os levam ao desânimo, em decorrência da baixa remune-

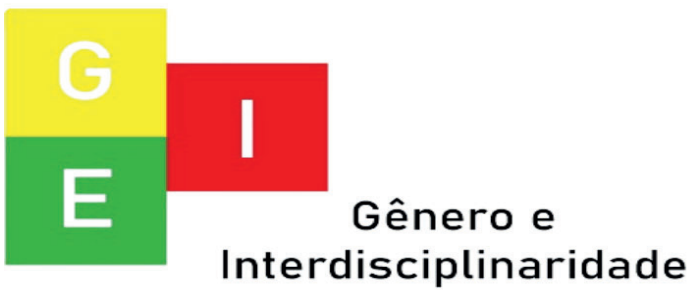


ISSN: 2675-7451

Vol. 02 - n 03 - ano 2021

Editora Acadêmica Periodicojs

ração (HYPOLITO, 1991).

No Brasil, hoje, ser professor não é uma das profissões promissoras em termos de salário e do reconhecimento social. O problema salarial que esses profissionais enfrentam parece ter mostrado profundas influências nos seus modelos pedagógicos. Muitos deles têm procurado outras formas de aumentar suas baixas remunerações.

De acordo com os achados na literatura (ALBUQUERQUE et al., 2010; ASSUNÇÃO e OLIVEIRA, 2009), ressaltam que o baixo salário, excesso de trabalho, sobrecarga entre outros, são fatores de maior influência para se prever mudanças nas práticas pedagógicas em sala de aula que podem levar o profissional docente ao adoecimento (ZIMMERMANN, 2000). Quando todo esforço e dedicação do profissional não são valorizados tanto pelo sistema educacional quanto pelo alunado e pais, a tendência do professor é desenvolver um sentimento de desânimo para a função desenvolvida, o que causará impacto no processo educacional.

A elevação do salário pago hoje ao docente brasileiro é uma meta do governo federal. É preciso maior investimento por parte dos governos federal, estadual e municipal para o resgate da valorização profissional. Sem uma remuneração adequada, não há como exigir do docente dedicação exclusiva ao magistério. Muitos continuam em salas de aulas, mas dividem seu tempo com outras atribuições profissionais. Tal divisão de seu horário compromete seu desempenho de pesquisador de métodos educativos que certamente ajudaria a elevar a qualidade do processo de aprendizagem de seus alunos.

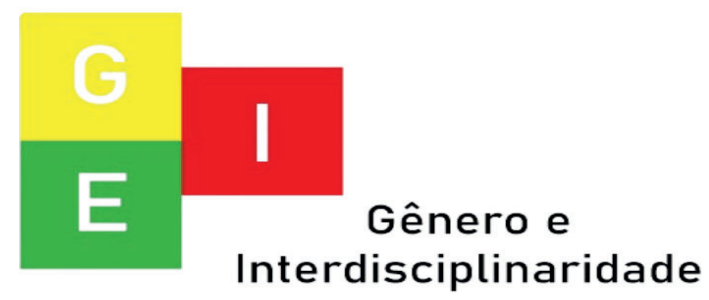


O esforço para o reconhecimento é de toda uma categoria profissional. Mas, durante muitas décadas não houve investimento dos governos em valorizar a profissão, não somente com melhores salários, mas também com condições e estruturas dos ambientes educacionais ideais para a melhoria da aprendizagem por parte dos alunos como de trabalho aos profissionais.

Além das condições de valorização dos professores, a precariedade das escolas não tem apresentado condições de acesso e permanência do aluno, comprometendo o rendimento e desempenho nas redes educacionais do sistema público, sobretudo, colocando o país nas últimas colocações dos indicadores de desempenho nacionais e internacionais.

Diante desse cenário, os dados e indicadores escolares do Brasil mostram certa realida- de do ensino no país como algo desafiador e, ao mesmo tempo, desperta uma preocupação. De acordo com o Programa Internacional de Avaliação dos Estudantes (PISA), realizado com o propósito de avaliar o desempenho escolar de diversos países, a situação do Brasil é desanimadora. Em conformidade com a edição do PISA aplicado em 2015, realizada com escolas de 70 países, o Brasil obteve a 59a colocação em leitura, e ficou entre os 10 últimos nas categorias de Matemática e Ciências (PISA, 2015).

$\mathrm{Na}$ última avaliação do PISA de 2018, conforme divulgada pela OCDE (Organização para Cooperação e Desenvolvimento Econômico), o Brasil ficou entre os 20 piores, no ranking internacional da educação. Foi analisado o desempenho de alunos de 15 anos, de 79 países. Apesar da melhora no ranking, em relação

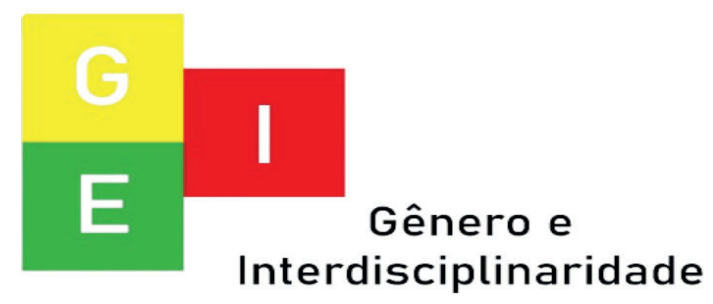


ISSN: 2675-7451

Vol. 02 - n 03 - ano 2021

Editora Acadêmica Periodicojs

à avaliação de 2015, o Brasil está atrás do Uruguai, Chile e México, nas três matérias avaliadas, e à frente de países latinos como a Argentina, a Colômbia e o Panamá em uma ou mais disciplinas avaliadas (BERMÚDEZ, 2019).

\section{Apontamento da importância da implantação da educação cí- vico-militar}

Atualmente, o país se vê diante do desafio de fomentar novos modelos educacionais de qualidade, capazes de elevar o nível de aprendizado que proporcionem aos jovens melhores oportunidades e condições mais favoráveis de inserção no mercado de trabalho, com a consequente redução da desigualdade social no país. O Governo Federal, ciente do seu papel frente a essa situação, estabelece o Decreto $\mathrm{N}^{\circ}$ 10.004, de 5 de setembro de 2019 , viabilizando o Programa Nacio-

nal das Escolas Cívico-Militares

(PECIM), que proporciona um modelo de gestão nas áreas educacional, didático-pedagógica e administrativa, alinhada à Base Nacional Comum Curricular (BNCC).

Art. 11. O modelo de Ecim é o conjunto de ações promovidas com vistas à gestão de excelência nas áreas educacional, didático-pedagógica e administrativa, baseada nos padrões de ensino adotados pelos colégios militares do Comando do Exército, das polícias militares e dos corpos de bombeiros militares.

$\S 1^{\circ} \mathrm{A}$ gestão na área educacional será alcançada por meio de ações destinadas ao desenvolvimento de comportamentos, valores e atitudes, com vistas ao desenvolvi-

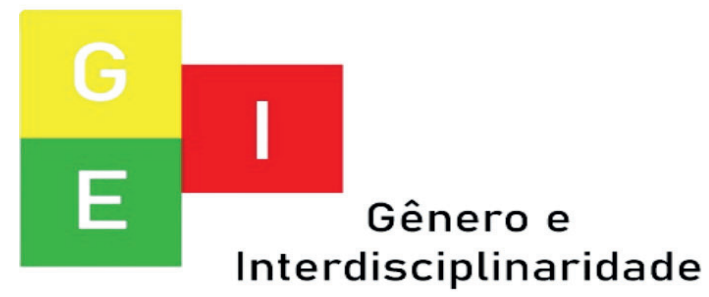


ISSN: 2675-745

Vol. 02 - n 03 - ano 202

Editora Acadêmica Periodicoj

mento pleno do aluno e ao seu preparo para o exercício da cidadania.

$\S 2^{\circ}$ A gestão na área didático-pedagógica será alcançada por meio de ações relacionadas à supervisão escolar, ao apoio pedagógico, à psicopedagogia, à avaliação educacional e à proposta pedagógica.

$\S 3^{\circ} \mathrm{A}$ gestão na área administrativa será alcançada por meio de ações que contemplem a administração, de forma sustentável, nas áreas de pessoal, de serviços gerais, de material, patrimonial e de finanças.

Art. 12. O modelo de Ecim deverá prever a realização de capacitação para todos os profissionais envolvidos no PECIM. (BRASIL, 2019, p. 4).
Nessa perspectiva, institui como base as experiências adquiridas nos modelos de alto nível educacional dos Colégios militares do Exército, da polícia Militar e do Corpo de Bombeiros militares, os quais têm apresentado melhores indicadores, em relação às escolas civis (BRASIL, 2019). Uma pesquisa realizada pelo Instituto Checon em todo o Brasil, que levou em consideração os aspectos como segurança, qualidade do ensino, disciplina dos alunos, respeito ao professor, preparo dos jovens para a vida e valores humanos e cívicos, constatou que $85 \%$ dos entrevistados manifestaram-se no sentido de que gostariam de ter seus filhos matriculados em escolas cívico-militares. O que levou o governo ao convencimento de que a adoção do modelo cívico-militar está de acordo com os anseios da população brasileira (BRASIL,

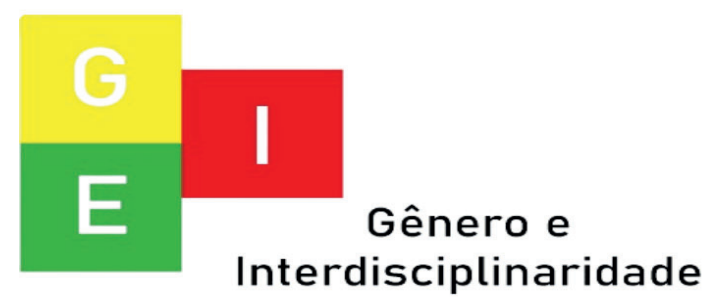


ISSN: 2675-7451

Vol. 02 - n 03 - ano 2021

Editora Acadêmica Periodicojs

2019).

Nessa direção, o decre-

Segundo o Governo Fe-

deral, o modelo proposto buscará fortalecer o civismo, o patriotismo, o respeito à família, aos professores e colegas, os valores éticos e morais, a organização e a disciplina. Valores esses que conduzirão os jovens a uma melhoria não só do seu desempenho escolar, mas também na formação de cidadãos conscientes da sua importância para o desenvolvimento do país. A proposta não prevê a substituição dos profissionais do corpo escolar e dos docentes. Isto é, a escola que adotar tal modelo, permanecerá com sua equipe de professores, entretanto, os militares assumem a administração escolar e a disciplina por meio de um código de conduta interna, visando uma mudança comportamental e atitudinal no ambiente escolar bem como na dimensão social. to $\mathrm{N}^{\mathrm{o}} 10.004 / 2019$ em seu artigo

$2^{\circ}$, inciso $\mathrm{V}$, ressalta que adotará uma gestão de processos educacionais voltadas à "promoção de atividades com vistas à difusão de valores humanos e cívicos para estimular o desenvolvimento de bons comportamentos e atitudes do aluno e a sua formação integral como cidadão em ambiente escolar externo à sala de aula" (BRASIL, 2019, p.1). Desta forma, o que se propõe é uma estruturação do ensino de forma que crie valores humanos baseados no respeito, na dedicação ao estudo, na moral e na ética, visando à melhoria do comportamento do aluno tanto no ambiente escolar quanto social. Consequentemente, o trabalho dos militares representa um alívio na carga do professor que passa a ter maior aproveitamento do tempo e a consequente melhora da qua-

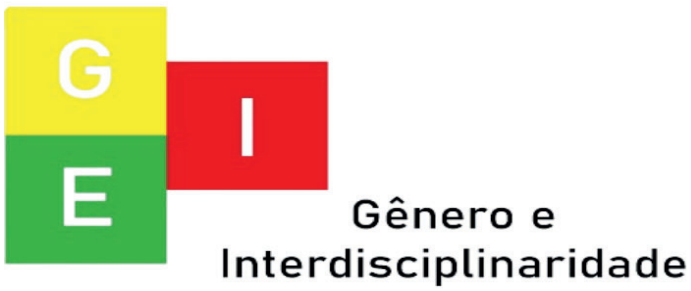


Vol. 02 - n 03 - ano 2021

Editora Acadêmica Periodicojs

lidade do processo ensino-aprendizagem.

O fenômeno da militarização tem apresentado intensa ampliação nos últimos anos. Entre 2013 e 2017, as escolas estaduais geridas pela Polícia Militar e Bombeiros saltaram de 39 para 122 em 18 estados e, até meados de 2019, registram-se 203 escolas militarizadas em 23 estados e no Distrito Federal. (PINHEIRO et al., 2019, p. 668).

Atualmente, o Brasil tem apresentado um total de 203 escolas cívico-militares, sendo estas instaladas em 23 unidades da Federação, as quais apresentam resultados positivos na avaliação nacional da educação básica. A meta do Governo traz em sua configuração a implementação de mais 216 escolas desse modelo até 2023. O projeto-piloto vai contemplar 54 escolas em 2020, duas por unidade da federação. Destas, 38 são escolas estaduais e 16 municipais, localizadas em 23 estados e no Distrito Federal.

Os colégios que queiram aderir devem ter de 500 a 1000 alunos matriculados do $6^{\circ}$ ao $9^{\circ}$ ano do ensino fundamental ou médio, em condições de vulnerabilidade social e cujas escolas indicadas apresentam baixo IDEB. O investimento será de um milhão de reais por escola. E a adesão dos Estados e Municípios é voluntária (BRASIL, 2019).

A atual realidade mostra que as notas do ENEM de 2017 das escolas cívico-militares foram superiores às das escolas estaduais comuns, de perfil semelhante. No recorte das melhores escolas, comparando-se institutos federais, militar federal,

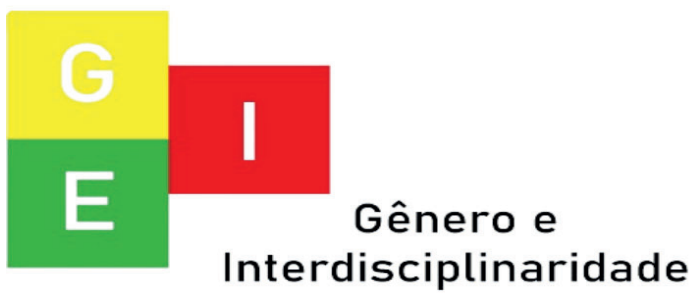


ISSN: $2675-7451$

Vol. 02 - n 03 - ano 2021

Editora Acadêmica Periodicojs

as cívico-militares e privadas, as notas são parecidas. Isso significa que o modelo cívico-militar é especialmente importante para elevar o desempenho dos estudantes mais pobres e vulneráveis.

As escolas cívico-militares são concorridas. Um colégio da PM em Teresina, por exemplo, recebeu em 2019, 1900 inscrições para 175 vagas. Em 2015, uma escola pública de Manaus, já bastante desgastada com graves episódios de violências, optou pelo modelo cívico-militar, o que gerou resultados de melhoria na ordem do ambiente escolar e, consequentemente, no desempenho dos alunos. Dessa forma, percebe-se que o Art. 1 e inciso $2^{\circ}$ do PECIM visa "complementar a outras políticas de melhoria da qualidade da educação básica em âmbito nacional, estadual, municipal e distrital e não implicará o encerramento de outros programas ou a sua substituição" (BRASIL, 2019, p.1). Isto é, o modelo cívico-militar não se propõe a substituir os atuais modelos, mas de resgatar o baixo padrão de comportamento e desempenho escolar por parte de alunos, além de assegurar melhores condições de segurança e valorização dos professores. No modelo proposto, os militares atuarão em apoio à gestão escolar e à gestão educacional, enquanto os professores continuarão responsáveis em seu trabalho em sala de aula, cumprindo a proposta didático-pedagógica estadual.

Sendo assim, o modelo, com o auxílio dos militares, estabelecerá um clima de autoridade e ordem no seio escolar, implantando um código de conduta que, ao contrário do que se possa imaginar, possibilitará ao aluno ficar mais focado no aprendizado, nos estudos, na melhoria do seu nível

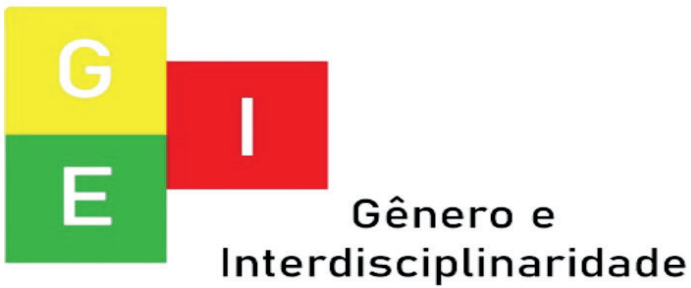


de escolaridade. Já que o excesso de liberdade, pelo que tudo indica, trouxe um clima permissividade nociva ao ambiente escolar, prejudicando o desenvolvimento do que realmente deve ser prioridade em sala de aula, o processo ensino-aprendizagem.

\section{O que diz as bases legais que} apoiam a implementação da educação cívico-militar?

\section{O Excelentíssimo $\mathrm{Sr}$.} Presidente da República, Jair Messias Bolsonaro, em um de seus primeiros atos como Presidente do Brasil, publicou o Decreto $n^{\circ} 9.665 / 19$, que trata da estrutura regimental e do quadro demonstrativo dos cargos em comissão e das funções de confiança do Ministério da Educação e que criava a Subsecretaria de Fomento às Escolas Cívico-Militares, delegando suas funções e competências (BRASIL, 2019).

No entanto, o Decreto $n^{\circ} 9.665$ (BRASIL, 2019) foi revogado pelo Decreto ${ }^{\circ} 10.195$, de 30 de dezembro de 2019 que está em vigência (BRASIL, 2019).

O Decreto $\mathrm{n}^{\mathrm{o}}$ 10.195, de 30 de dezembro de 2019, aprova a Estrutura Regimental e o Quadro Demonstrativo dos Cargos em Comissão e das Funções de Confiança do Ministério da Educação, remanejando e transformando cargos em comissão e funções de confiança. Com o Decreto foi reestruturado o Ministério da Educação (MEC) e atribuído à Secretaria de Educação Básica:

Fomentar, acompanhar e avaliar, por meio de parcerias, a adoção por adesão do modelo de escolas cívico-militares nos sistemas de ensino estaduais, distrital e municipais, que adotarão a ges-

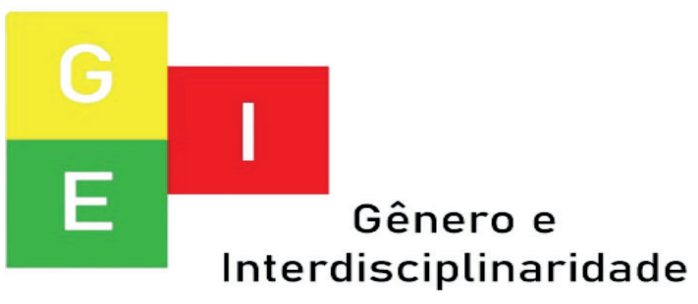


ISSN: 2675-7451

Vol. 02 - n 03 - ano 2021

Editora Acadêmica Periodicojs

tão administrativa, litares ${ }^{1}$, cujas competências, são

educacional e didá-

tico-pedagógica dos

colégios militares do

Exército, das Polí-

cias Militares e dos

Corpos de Bombeiros Militares. (BRASIL, 2019, p. 4).

definidas no art. 15 do Decreto $\mathrm{n}^{\circ}$ 10.195.

O decreto delega à Dire-

toria de Políticas para Escolas Cívico-Militares à incumbência de promover, gradualmente, a aprovação das escolas ao modelo cí-

No anexo I do Decreto vico-militar, ainda que por meio de adesão voluntária. À unidade compete ainda criar, gerenciar e coordenar programas nos campos didático-pedagógicos e de gestão educacional, como são descritas no art. 15:

Art. 15. À Diretoria de Políticas para Escolas Cívico-Militares compete:

I - formular, coorde-

da Educação poderá estabelecer

parcerias com instituições civis

e militares que apresentam expenar, monitorar e avaliar a implementação de políticas, programas e ações para es-

riências exitosas em educação" (BRASIL, 2019, p. 1). No mesmo decreto foi criada a Diretoria de Políticas para Escolas Cívico-Mi-

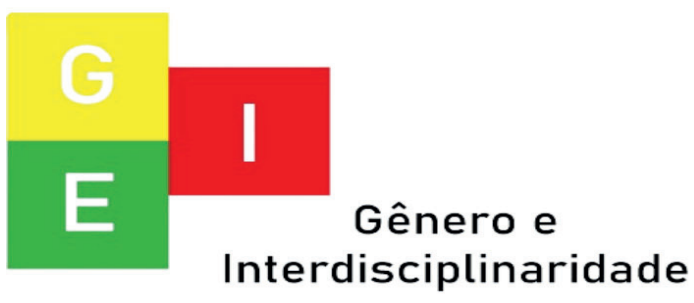


ISSN: 2675-745

Vol. 02 - n 03 - ano 202

Editora Acadêmica Periodicoj

colas cívico-milita-

res;

II - formular mode-

lo educacional com

base nos padrões

de ensino e gestão

empregados nos co-

légios militares do

Exército, das Polí-

cias Militares e dos

Corpos de Bombeiros Militares, para os

ensinos fundamental

e médio, em conso-

nância com a legis-

lação educacional

vigente;

III - promover o modelo de escola cívico-militar mediante adesão voluntária, que atenda, preferencialmente, escolas em situação de vulnerabilidade;

IV - estimular a cooperação com os órgãos dos entes federativos e entidades públicas e privadas para a implementação do modelo de escola cívico-militar; $\mathrm{V}$ - incentivar a par- ticipação da comunidade escolar nas escolas cívico-militares;

VI - desenvolver e monitorar o sistema de cadastramento, avaliação e acompanhamento das atividades das escolas cívico-militares;

VII - elaborar e acompanhar estudos para o aprimoramento das práticas de gestão e de ensino das escolas cívico-militares;

VIII - desenvolver e avaliar tecnologias destinadas ao planejamento e às boas práticas gerenciais das escolas cívico-militares; e

IX - propor e acompanhar a elaboração de cursos de capacitação para atuação em escolas cívico-militares. (BRASIL, 2019, p. 5).

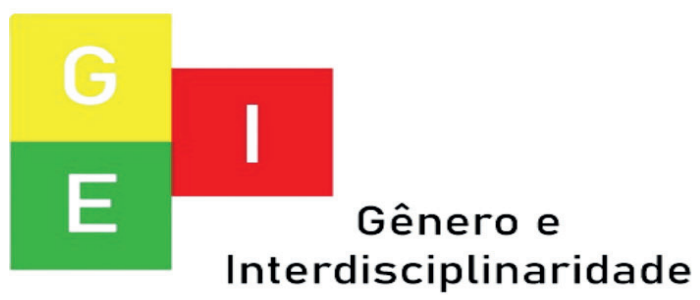


ISSN: $2675-7451$

Vol. 02 - n 03 - ano 2021

Editora Acadêmica Periodicojs

Percebe-se a preocupa- no das escolas cívico-militares.

ção do governo em melhorar a Além de desenvolver e avaliar

qualidade do ensino fundamen- as metodologias direcionadas ao

tal e médio, principalmente em planejamento bem como às práti-

escolas com situação de vulnera- cas gerenciais das unidades esco-

bilidade, fazendo parcerias com lares do modelo cívico-militares;

instituições militares que tem desenvolver articulações para a

nos Colégios Militares inúmeras estruturação instrucional de cur-

experiências exitosas na educa- sos de qualificação, em coautoria ção.

com as gerencias da Secretaria;

O texto inclui também, propor sugestões e acompanhar

as atribuições das futuras escolas o desenvolvimento e evolução de

cívico-militares, como atribui- sistemas que promova o controle

ção de avaliar as demandas dos dos projetos de cursos de capaci-

pedidos de manutenção, con- tação, gestão, técnicos, docentes,

servação e reformas das novas formação continuada de gestores,

instalações das escolas cívico- parceiros e outros profissionais

-militares, também em propor, colaboradores (BRASIL, 2019).

desenvolver e acompanhar a di- A criação da Subsecre-

nâmica de cadastramento, avalia- taria de Fomento às Escolas Cí-

ção e monitoramento das ações vico-Militares (Decreto $n^{0} 9.665$

desempenhadas pelas unidades em 2 de janeiro de 2019) que foi

escolares de modelo cívico-mi- transformada em Diretoria de

litares, e também estudos para Políticas para Escolas Cívico-

aprimoramento da organização -Militares pelo Decreto n ${ }^{0}$ 10.195,

técnico-pedagógica do ensi- de 30 de dezembro de 2019, foi




o primeiro passo para criação do programa do Governo Federal que promove o modelo de escolas cívico-militares nos sistemas de ensino municipais, estaduais e distrital. Porém, é bom ressaltar que no Brasil já existem escolas cívico-militares financiadas por Secretarias Estaduais de Segurança Pública e Secretarias Estaduais de Educação, no qual os aspectos legais e financeiros da parceira são definidos entre as instituições militares e as secretárias estaduais de Educação sob a luz da Constituição Federal e das Leis de Diretrizes e Bases da Educação (BRASL, 1988;1996).

Seguindo com as intenções do governo de ampliar/criar escolas cívico-militares, no dia 5 de setembro de 2019 foi promulgado o Decreto $\mathrm{N}^{\mathrm{o}} 10.004$, assinado pelo Excelentíssimo Sr. Presidente da República Jair Messias Bolsonaro, que instituiu o Pro- grama Nacional das Escolas Cívico-Militares (PECIM). O Programa tem a finalidade "[...] de promover a melhoria na qualidade da educação básica, no ensino fundamental e no ensino médio" (BRASIL, 2019, p. 1). Assim, iniciativas como o PECIM podem ajudar na melhoria da qualidade do ensino no Brasil, estando de acordo com o art. 206 da Constituição Federal que estabelece, no seu inciso VII, que o ensino no Brasil será ministrado com base no princípio da garantia do padrão de qualidade (BRASIL, 1988).

De acordo com o Decreto, o Programa será desenvolvido pelo Ministério da Educação com o auxílio do Ministério da Defesa e realizado em colaboração com os Estados, os Municípios e o Distrito Federal para promover atividades direcionadas ao fortalecimento das Escolas Cívico-

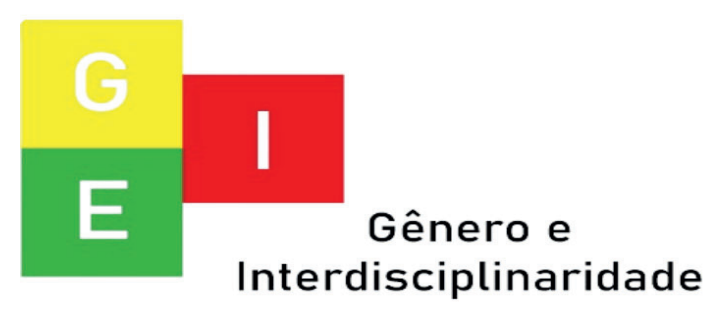


Vol. 02 - n 03 - ano 2021

Editora Acadêmica Periodicojs

-Militares (ECIM). Nessa mesma direção a LDB 9.394/96 no seu art. $9^{\circ}$, inciso III, também enfatiza que à União ofereça suporte técnico e financeiro para esferas do campo estadual, distrital e municipal visando a melhoria nos sistemas de ensino (BRASIL, 1996).

Ainda em suas disposições gerais, o decreto traz que o PECIM surgiu como forma complementar de outras políticas para a melhoria da qualidade educacional básica dentro do âmbito Federal, Estadual, Municipal e Distrito Federal, sem intenção de substituir ou comprometer a existência de outros projetos e programas que visam a melhoria do sistema de ensino nas escolas públicas (BRASIL, 2019).

Em síntese, o PECIM consiste em transferir à Polícia Militar a gestão educacional e administração das escolas públicas (apenas as que forem submetidas ao projeto), enquanto a parte pedagógica (professores e métodos de ensino) segue sob o alcance da Secretaria de Educação.

Os princípios do PECIM descritos no art. 3 do Decreto são bem claros e buscam uma gestão de excelência nas áreas educacional, didático-pedagógica e administrativa. Além disso, uma das bases do projeto é o apoio técnico e financeiro designado tanto para as unidades escolares públicas de ensino regular que manifestaram preferência em aderir ao PECIM quanto para aquelas já que adotam o modelo de gestão com parceria dos órgãos civil/militar, para alinhar ao modelo.

É também princípio do PECIM buscar a realização de atividades que promovam os valores humanos, morais e cívicos para estimular o desenvolvimento de bons comportamentos e ati-

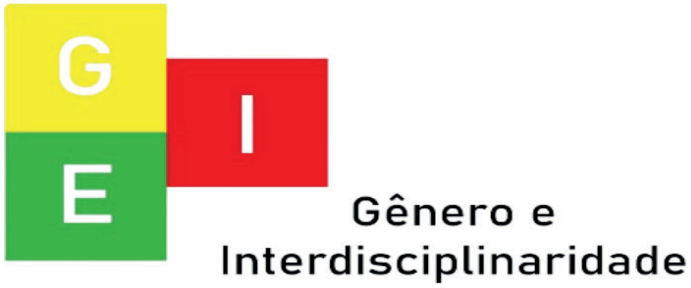


ISSN: 2675-745

Vol. 02 - n 03 - ano 202

tudes do aluno e a sua formação

integral como cidadão em socie-

dade. Os princípios do PECIM

são:

Art. $3^{\circ}$ São princípios do PECIM:

I - a promoção de educação básica de qualidade aos alunos das escolas públicas regulares estaduais, municipais e distritais;

II - o atendimento preferencial às escolas públicas regulares em situação de vulnerabilidade social;

III - o desenvolvimento de ambiente escolar adequado que promova a melhoria do processo ensino-aprendizagem;

IV - a articulação e a cooperação entre os entes federativos; V - a gestão de excelência em processos educacionais, didático-pedagógicos e administrativos;

\section{Editora Acadêmica Periodico}

VI - o fortalecimento de valores humanos e cívicos;

VII - a adoção de modelo de gestão escolar baseado nos colégios militares; VIII - a indução de boas práticas para a melhoria da qualidade do ensino público; e

IX - a adoção de modelo de gestão que proporcione a igualdade de oportunidades de acesso à educação. (BRASIL, 2019, 1).

É possível perceber a intenção da otimização dos recursos materiais e financeiros da unidade escolar, por meio de modelos de gestão de processos didático-pedagógicos e de processos administrativos. Isso possivelmente irá evitar desperdício e irá gerar economia de recursos.

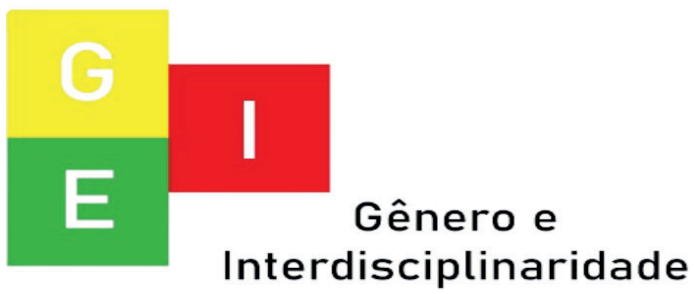




\section{CONCLUSÃO}

Partindo do ponto de vista complexo das questões discutidas, tratadas e, sobretudo, dos dados analisados no universo deste estudo, foi possível formular uma síntese conclusiva, apresentando um conjunto de conclusões na tentativa de mostrar a dimensão do olhar sobre o cenário atual acerca da qualidade da educação básica em escolas públicas e a concepção do modelo educacional cívico-militar. $\mathrm{Na}$ perspectiva do direito à educação com qualidade o modelo cívico-militar pode contribuir para a melhoria do comportamento de alunos no ambiente familiar, escolar e social. Bem como, entende-se que há relevância da parceria dos órgãos militares com a escola pública para melhoraria da qualidade da educação básica com ênfase no acesso, na perma- nência e na aprendizagem, signi-

ficativamente.

Com isso, portanto, é possível demonstrar que o modelo educacional cívico-militar faz com que o professor se sinta valorizado, contribui para a valorização também de gestores e demais profissionais da educação, assim como promove valores morais, cívicos e patrióticos da sociedade e melhora o desempenho dos alunos da escola pública nas avaliações externas de largar escala. Além disso, garante suporte a gestão administrativa, pedagógicas e recursos que consolidam a aprendizagem com qualidade e eficiência do aluno e facilita a dinâmica de ensino do docente.

\section{Referências}

ASSUNÇÃO, Ada Ávila; OLIVEIRA, Dalila Andrade. Intensificação do trabalho e saúde dos

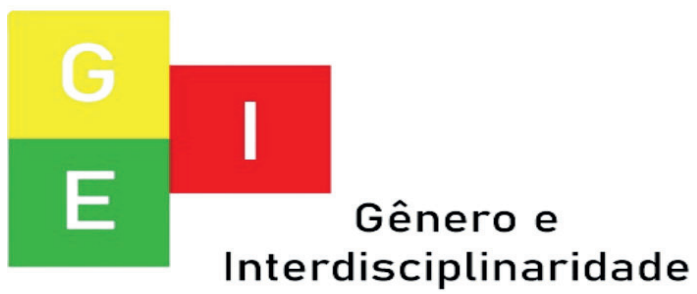


professores. Educação \& Sociedade, v. 30 , n. 107 , p. 349-372, 2009.

ALBUQUERQUE, Elizabete Elias de; COSTA, Sileide Leite; RIBAS, Valdenilson Ribeiro; ALMEIDA, Pedro Ivo Leite de; LOPES, Elizangela Maria das Neves; MAGALHÃES-FILHO, Enoelino; SIQUEIRA, Cristiano do Nascimento; ANDRADE, Paulo Henrique da Silva; GOMES, Manoel Dinamérito de Oliveira; MANHÃES DE CASTRO, Raul. Professores do Ensino Fundamental do Município de Quipapá/PE Apresentam Estresse. Neurobiologia, v.73, n. 1, 117125, 2010.

BERMÚdEZ, Ana Carla. Pisa: Brasil fica entre piores, mas à frente da Argentina. 2019. Disponível no site: https://educacao. uol.com.br/noticias/2019/12/03/ pisa-brasil-fica-entre-piores-

-mas-a-frente-da-argentina-veja-ranking.htm. Acesso em: 29/03/ 2021.

BRASIL. Decreto $n^{\circ} 10.195$, de 30 de dezembro de 2019d. Disponível no site: http://www.planalto.gov.br/ccivil_03/_ato20192022/2019/Decreto/D10195. htm\#art8. Acesso em: 20/01/ 2020. . Ministério da Educação. Entenda as diferenças entre os modelos de escolas cívico-militares propostos pelo MEC. $2019 \mathrm{f}$. Disponível no site: http://portal. mec.gov.br/compone.t/content/ article/211-noticias/218175739/ 81851-entenda-as-diferencas-entre-os-modelos-de-escolas-civico-militares-propostos-pelo-mec?Itemid=164. Acesso em 20/01/ 2020.

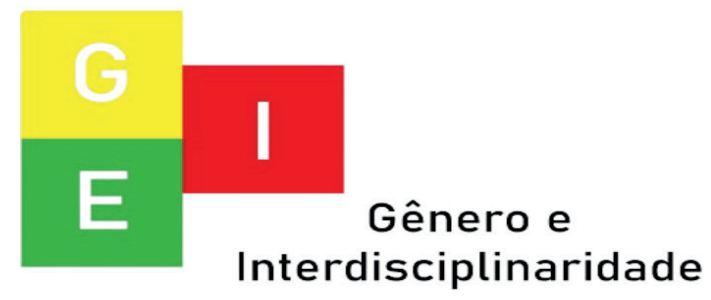


ISSN: $2675-7451$

Vol. 02 - n 03 - ano 2021

Editora Acadêmica Periodicojs

- Ministério da Edu- 5 de setembro de 2019a. Dispo-

cação. Governo federal lança nível no site: http://www.pla-

programa para a implantação de nalto.gov.br/ccivil_03/_ato2019-

escolas cívico-militares. 2019b. 2022/2019/decreto/D10004.htm.

Disponível no site: http://portal. Acesso em 20/01/ 2020.

mec.gov.br/busca-geral/211-no-

ticias/218175739/79931-governo. Lei de Diretrizes e

-federal-lanca-programa-para-

-a-implantacao-de-escolas-civi-

co-militares; Acesso em 20/01/

2020.

. Lei n. 8.069, de 13 de Constituição da Repú-

julho de 1990. Dispõe sobre Esta-

blica Federativa do Brasil.1988. tuto da Criança e do Adolescente

Disponível no site: <http://www. e dá outras providências. Brasí-

planalto.gov.br/ccivil_03/consti-

lia, DF: DOU, 1990.

tuicao/constituicao.htm>. Acesso

.Manual das escolas cíem: 05/03/2013.

vico-miliares. 2020c. Disponível

.Decreto n. 9465 , de 2

no site: http://www.consultaesic.

de janeiro de 2019c. Disponível

cgu.gov.br/busca/dados/Lists/Pe-

no site: http://www.in.gov.br/ma-

dido/Attachments/837270/RES-

teria/-/asset_publisher/Kujrw0T-

POSTA_PEDIDO_ECIM_Final.

ZC2Mb/content/id/57633286.

pdf. Acesso em: 22/03/ 2020.

Acesso em 20/01/ 2020.

HYPOLITO, Álvaro Moreira.

Decreto $\mathrm{n}^{\mathrm{o}} 10.004$, de Processo de trabalho na escola:

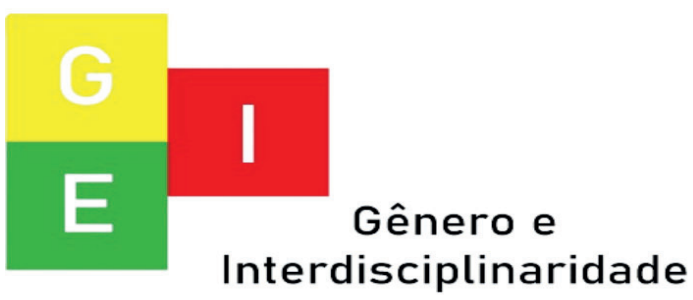


algumas categorias para anáíúa.

Teoria S Educação, n. 0, p. 4, 1991.

SAVANI, Dermeval. A pedagogia histórico-crítica. Revista RBBA, Vitória da Conquista V. 3 no 02 p. 11-36, 2014.

SILVA-FILHO, Raimundo Barbosa; ARAÚJO, Ronaldo Marcos de Lima. Evasão e abandono escolar na educação básica no Brasil: fatores, causas e possíveis consequências. Educação Por Escrito, Porto Alegre, v. 8, n. 1, p. 35-48, 2017.

ZIMMERMANN, E. Modelos

de pedagogia de professores de física: características e desenvolvimento.Caderno Catarinense de Ensino de Física, Florianópolis, v. 17, n. 2, p. 150-173, 2000.

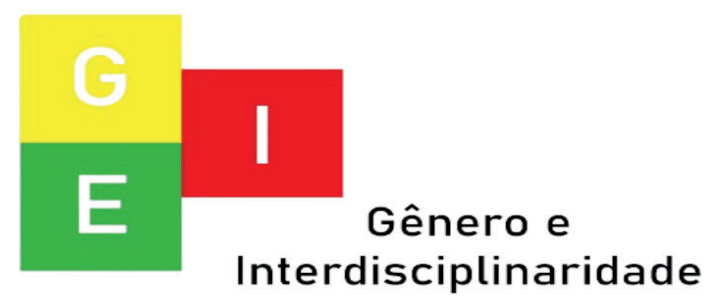

